\title{
Erosive and Pustular Dermatitis of the Scalp, an Under Recognized Condition. Case Reports and Review
}

\author{
Carol R. Drucker* \\ Department of Dermatology, The University of Texas M. D. Anderson Cancer Center, Houston, Texas, USA
}

Received: April 01, 2016; Accepted: April 20, 2016; Published: April 28, 2016

*Corresponding author: Carol R. Drucker, MD, Department of Dermatology, The University of Texas M. D. Anderson Cancer Center, 1515 Holcombe Blvd. Unit 1452, Houston, Texas 77381, USA, Tel: 713-745-5736; Fax: 713-745-3597; E-mail: crdrucker@mdanderson.org

\begin{abstract}
Erosive pustular dermatitis of the scalp has been reported as a rare chronic and progressive inflammatory condition of the actinically damaged scalp characterized by crusts, erosions and pustules. Less than 150 cases have been reported worldwide. I present 4 representative cases, review the world literature on the condition and postulate the condition is more common than diagnosed. No single treatment has been constantly acceptable, but a review of treatments used to date can help clinicians deal with this difficult to treat chronic condition. Increased awareness of and proper diagnosis of this condition changes the approach to treatment of these patients and while giving them a better outcome, keeps the clinician vigilant of squamous cell carcinomas that can arise in this skin.
\end{abstract}

\section{Introduction}

Erosive Pustular Dermatosis of the Scalp (EPDS) is an inflammatory process of unknown etiology. It is characterized by pustules, erosions and crusts on atrophic, actinically damaged skin in areas of alopecia. It tends to occur on the scalp of older people who have usually been treated for diffuse actinic damage and actinic keratoses. Some have had squamous cell carcinoma in the field involved. All have been reported to occur after trauma, including previous treatments for actinic keratoses and generally after stronger or more extensive treatments. As such, the condition tends to initially be approached as chronic and extensive actinically damaged skin with actinic keratoses, some hyperkeratotic, with the need to be clinically alert for development of squamous cell carcinomas.

In the chronic course of this treatment, after an inciting trauma of one type or another, the patient's scalp quits responding to typical treatment for actinic keratoses, and becomes a chronic process of inflammation, erosions, crusts and pustules on a background of atrophic, actinically damaged skin, sometimes resulting in scarring alopecia.

Notoriously difficult to treat, these cases tend to be chronic and progressive. These patients often present after repeated treatments to actinic keratoses which have not lead to clearing, but to persistent new lesions and perpetuation of the process.

I postulate the disease process is more common than is implied by the 150 or so reported cases would imply. Most likely a number of these patients continue to receive treatment for actinic keratoses, but eventually it becomes apparent the lesions are no longer responding, maybe even worsening with the treatment. I believe the presentation of the review of this entity should serve to increase awareness among those of us who treat these patients so that more appropriate treatment can be instituted.

Recognition of the process can help steer treatment away from destructive treatments to anti-inflammatory treatments. I present four representative cases and a review of the disease, its precipitating traumas, its histology, and reported treatments in an effort to increase awareness of the condition so that proper treatment may ensue.

\section{Patient 1}

An 82 year old man presented with dermatitis of the scalp having been seen for years for actinic keratoses. He had numerous treatments with cryotherapy, trichloracetic acid peels, and 5 fluorouracil field therapy. In the year before presentation, he had developed a chronic crusting of the scalp. Sometimes pustules developed but it always remained crusty. Several biopsies were done and variously showed actinic keratoses, inflammation, and granulation tissue.

Compresses with Domeboro did not help. January 2014, he was started on tacrolimus ointment for erosive pustular dermatitis of the scalp. It burned upon application and lesions sometimes bled, but dramatic results were noted in the first month. He discontinued it within the month because of the intolerable burning with application. The burn occurred even if he applied Aquaphor first. April 2014 he presented with red and painful scalp, and minocycline for secondary infection cleared that. Later that month, he was started on acitretin $10 \mathrm{mg}$ daily. His scalp improved markedly, and he stayed on this until October 2014. After he stopped it, crusting and drainage worsened. He was restarted on acitretin within one month at a higher dose of $17.5 \mathrm{mg}$. Although the scalp continued to be involved, he had improvement with crust but without drainage, bleeding or pain; it did itch. 
At that point underlying metastatic bladder cell carcinoma progressed. He was placed on hospice care, and with markedly increasing fatigue, he discontinued the acitretin. Topical steroids and emollients did not help, and the crusting and drainage worsened.

\section{Patient 2}

A 78 year old female was referred with a history of nonhealing lesion of the scalp. This site had biopsy shown squamous cell carcinoma in November 2011. Pathology from the original MOHS surgery December 2011 showed skin and subcutis with dermal scar and chronic inflammation with no squamous cell carcinoma identified. When next seen in February 2013, the site had never healed. Biopsy of the non-healing skin showed granulation tissue and ulceration. This site was treated with silver nitrate and improved but persisted. Repeat biopsy of the site June 2013 showed squamous cell carcinoma in situ arising in association with actinic keratosis. The positive margins were treated with cryotherapy. She presented October 2013 with persistent non healing of the site; another biopsy showed superficial dermal scar and actinic changes. When she was seen again with the persistent wound February 2014, she was thought to have inflammatory and pustular dermatitis of the scalp. Tacrolimus was prescribed but not filled by the patient due to the cost. Follow up was delayed due to other medical issues requiring hospitalization and intravenous antibiotics. Conservative treatment was used during this time with steroid ointment. The site improved. When last seen in May 2015 the vertex scalp had two adherent hard whitish scales with no visible growth beneath them. No erosions or pustules were noted, and she felt the site had improved markedly. She was managed conservatively with Aquaphor. Unfortunately she succumbed to septic shock September 2015.

\section{Patient 3}

A 62 year old male presented in November 2010 with a history of chronic actinic keratoses of the vertex scalp, treated repeatedly with cryotherapy. Biopsy in 2007 showed spongiotic dermatitis and in 2008 another biopsy showed the surface of probable folliculitis. On presentation November 2010 the scalp showed erythema with at least 3 very adherent white hyperkeratotic scales on erythematous bases, and biopsy showed actinic keratosis and dermal scar both present at the edges of the biopsy specimen. He received cryotherapy to the sites. When he was seen again December 2011 vertex scalp showed confluent erythema with smaller distinct hyperkeratotic lesions. The isolated lesions were treated with cryotherapy, and he was started on minocycline. By February 2012 his problem of skin lesions continued to clinically appear to be hypertrophic actinic keratoses but did not respond like them, and with a diagnosis of inflammatory process with scarring, he was started on clobetasol foam. On his next follow up April 2012 he was responding to the topical steroid. Follow up two months later showed fewer crusts and he was continued on the topical steroid, and by April 2015 the scalp was essentially resolved with the topical steroids and was thought to have been EPDS.

\section{Patient 4}

A 68 year old male was first seen with a history of squamous cell carcinoma of the scalp and a history of many actinic keratoses of the scalp previously treated with cryotherapy. A year later, among other actinic keratoses treated with cryotherapy, another squamous cell carcinoma was diagnosed and treated with curettage and electrodessication. A recheck of the site a month later showed granulation tissue and silver nitrate application cleared this. Further cryotherapy was used to multiple actinic keratoses on his scalp over the next year, but by February 2015 it was felt the treatment was not working anymore. Biopsy then showed dermal fibrosis and atypia of basal keratinocytes present at the edges of the specimen. Curettage and desiccation of another squamous cell carcinoma at the frontal scalp resulted in granulation tissue and was treated with silver nitrate and responded. At the next follow up, hyperkeratotic and erosive lesions persisted and with the diagnosis of EPDS, the patient opted to follow for progressing lesions of squamous cell carcinoma but discontinue the regular cryotherapy to existing lesions. Further visits are pending.

\section{Clinical Review}

EPDS was first described by Burton [1] in 1987 and Pye et al [2] in 1979. Over 100 cases have been reported worldwide since, with the first cases reported in the United States by Patton et al [3]. The typical presentation is in the setting of chronically and markedly actinically damaged skin of the scalp, with crusty and eroded lesions which can be mistaken for actinic keratoses or squamous cell carcinomas. Importantly, most patients start with actinic lesions of the scalp and have been serially treated for actinic keratoses; some have had development of squamous cell carcinomas. However, at some point during treatment, the lesions become more chronic, progressive and inflammatory, and they no longer respond to previously used treatments for the actinic keratoses. This marked change has been regularly attributed to a specific precipitating trauma, usually a treatment aimed at the actinic lesions.

\section{Preceding Traumas}

The traumas which have been reported to precede the development of this chronic progressive process are usually related to the destruction of the original actinic lesions, but some cases have been reported to unrelated traumas.

A review of the culprit trauma preceding the development of EPDS includes:

Cryotherapy [3-5] fluorouracil [3,5,6] imiquimod [7,8] tretinoin [4], ingenol mebutate [9], radiation therapy [10-12] CO2 Laser [3,13] photodynamic therapy [14,15] surgery [1618], skin grafting [17,19-21], hair transplantation [22], minoxidil treatment [23], lantanoprost application [24], herpes zoster [2528], birth trauma [29].

The disease itself is characterized by erosions and crusts; pustules can be found and are initially sterile [30]. Treatment of secondary infection, most commonly staphylococcal aureus [31] does not clear the process. 


\section{Comorbidities}

Isolated cases in patients with concomitant autoimmune diseases are sometimes noted including rheumatoid arthritis $[32,33]$, autoimmune hepatitis, Hashimoto's thyroiditis, Takayasu arteritis [34], myasthenia gravis [35]. Positive antibodies for autoimmune diseases are sometimes found [36-38] but are not considered necessary for or germane to the diagnosis.

Likewise, other isolated cases of associated comorbidities including myelodysplastic syndrome [39], metastatic lung cancer [11], and metastatic renal cell carcinoma (Patient 1) have been reported. However, considering the population prone to this disorder is largely the elderly, comorbidities would not be unusual and would not suggest significance of association.

\section{Histology}

Histology is not diagnostic. Pathology shows actinic damage and the presence of enlarged keratinocytes at the edges of ulcers which may lead to the misdiagnosis of actinic keratosis or poor healing in actinically damaged skin.

The epidermis may be normal, with hyperkeratosis and parakeratosis, erosion, or atrophy; with or without edema and subcorneal pustules $[40,36]$. The dermis may contain chronic inflammatory infiltrate and plasma cells with neutrophils, especially in the upper dermis [40,34]. Phagocytosis and giant cells can be seen around hair shafts in the deep dermis with follicle destruction. Dermal fibrosis and atrophy of hair follicles with loss of elastic tissue can be seen [36]. Granulation tissue changes have also been seen.

\section{Treatment}

A number of treatments have been reported used to treat EPDS. An occasional treatment, such as photodynamic therapy, has been reported to precipitate $[14,15]$ and to treat [41-43] the condition. Treatments reported have not been consistently effective or been adopted to be used as a standard.

Treatments reported to help have included potent topical steroids [44, 2], oral steroids [45, 15], and intralesional steroids [46] but relapse with discontinuation is common [47]. Other reported treatments have been oral isotretinoin $[47,36,5]$, oral zinc sulfate [24, 48], calcipotriol [49], tacrolimus [32, 39, 45, 50 , $51,25,16,46,52,53]$, topical dapsone [54], acitretin [55, current cases], cyclopsorin [56], surgery [57].

\section{Discussion}

EPDS has no pathognomonic laboratory or histologic findings and is a clinical diagnosis of exclusion [55].

EPDS has been considered rare but is likely more common but under recognized. Since it commonly develops in the actinically damaged scalp skin and manifests as superficial erosion and crusts with or without pustules on atrophic skin, proper diagnosis is important as further destructive treatments to suspected actinic keratoses perpetuate the process. The disease must be followed closely clinically as squamous cell carcinomas do occur in this setting. No distinct treatment has been successful in all cases, but patients need treatment for pain and pruritus associated with the process.

Dermatologists should be on alert for EPDS when treating the common actinically damaged scalp, as these two similarly appearing clinical conditions require markedly different approach to management.

\section{References}

1. Burton JL. Case for diagnosis: pustular dermatosis of the scalp. Br J Dermatol. 2006;97(Supp 15):67-68.

2. Pye RJ, Peachey RD, Burton JL. Erosive pustular dermatosis of the scalp. Br J Dermatol. 1979;100(5):559-566.

3. Patton D, Lynch PJ, Fung MA, Fazel N. Chronic atrophic erosive dermatosis of the scalp and extremities: A recharacterization of erosive pustular dermatosis. J Am Acad Dermatol. 2007;57(3):421427.

4. Rongioletti F, Delmonte S, Rossi ME, Strani GF, Rebora A. Erosive pustular dermatosis of the scalp following cryotherapy and topical tretinoin for actinic keratoses. Clin Exp Dermatol. 1999;24(6):499500 .

5. Laffitte E, Panizzon RG, Saurat JH, Emmanuel, Renato G, Jean-Hilaire. Delayed wound healing on the scalp following treatment of actinic keratoses: Erosive pustular dermatosis of the scalp. Dermatol Surg. 2004;30(12 Pt 2):1610.

6. Bonerandi JJ. Erosive and pustular scalp diseases. Ann Dermatol Venereol. 1999;126(4):311-312.

7. Corradin MT, Forcione M, Giulione E, Fiorentino R, Ferrazzi A, Alaibac M. Erosive pustular dermatosis of the scalp induced by imiquimod. Case Rep Dermatol Med. 2012;2012:828749. Doi:10.1155/2012/828749.

8. Vaccaro M, Barbuzza O, Guarneri B. Erosive pustular dermatosis of the scalp following treatment with topical imiquimod for actinic keratosis. Arch Dermatol. 2009;145(11):1340-1341. doi: 10.1001/ archdermatol.2009.278

9. Rongioletti F, Chinazzo C, Javor S. Erosive pustular dermatosis of the scalp induced by ingenol mebutate. J Eur Acad Dermatol Venereol. 2015. Doi: $10.1111 / j d v .13350$.

10. Skellett AM, Levell NJ. Erosive pustular dermatosis and osteoradionecrosis: complications of radiotherapy. Clin Exp Dermatol. 2011;36(1):98-99. doi:10.1111/j.1365-2230.2010.03887.x.

11. Wu CY, Chen GS, Lan CC. Erosive pustular dermatosis of the scalp after gefitinib and radiotherapy for brain metastases secondary to lung cancer. Clin Exp Dermatol. 2008;33(1):106-107.

12. Trueb RM, Krasovec M. Erosive pustular dermatosis of the scalp following radiation therapy for solar keratoses. $\mathrm{Br} J$ Dermatol. 1999;141(4):763-765.

13. Tavares-Bello R. Erosive pustular dermatosis of the scalp. A chronic recalcitrant dermatosis developed upon CO2 laser treatment. Dermatology. 2009;219(1):71-72. doi: 10.1159/000210430

14. Lopez V, Lopez I, Ramos V, Ricart JM. Erosive pustular dermatosis of the scalp after photodynamic therapy. Dermatol Online J. 2012;18(9):13.

15. Guarneri C, Vaccaro M. Erosive pustular dermatosis of the scalp following topical methylaminolaevulinate photodynamic therapy. J Am Acad Dermatol. 2009;60(3):521-522.

16. Marzano AV, Ghislanzoni M, Zaghis A, Spinelli D, Crosti C. Localized erosive pustular dermatosis of the scalp at the site of a cochlear implant: 
successful treatment with topical tacrolimus. Clin Exp Dermatol 2009;34(5):e157-159. doi: 10.1111/j.1365-2230.2008.03054.x

17. Mehmi M, Abdullah A. Erosive pustular dermatosis of the scalp occurring after partial thickness skin graft for squamous cell carcinoma. Br J Plast Surg. 2004:57(8):806-807.

18. Layton AM, Cunliffe WF. Erosive pustular dermatosis of the scalp following surgery. Br J Dermatol. 1995;132(3):472-473.

19. Martin FJ, Herrera A, Rios JJ, Moreno JC, Camacho F. Erosive pustular dermatosis of the scalp after skin grafting. Dermatol Surg. 2001;27(8):766-767.

20. Drouin CA, Cloutier RA. Recurrence of erosive pustular scalp dermatosis after a skin graft. Ann Dermatol Venereol. 1999;126(4):335-338.

21. Ena P, Lissia M, Doneddu GM, Campus GV. Erosive pustular dermatosis of the scalp in skin grafts: report of three cases. Dermatology. 1997;194(1):80-84.

22. Shahmoradi Z, Abtahi-Naeini B, Pourazizi M. Erosive pustular dermatosis of the scalp following hair transplantation. Adv Biomed Res. 2014;3:176. doi: 10.4103/2277-9175.139412

23. Guarneri C, Cannavo SP. Erosive pustular dermatosis of the scalp from topical Minoxidil 5\% solution. Int J Dermatol. 2013;52(4):507509. doi: $10.1111 / \mathrm{j} .1365-4632.2011 .04890 . x$

24. Vaccaro M, Barbuzza O, Borgia F, Cannavo SP. Erosive pustular dermatosis of the scalp following topical latanoprost for androgenetic alopecia. Dermatol Ther. 2015;28(2):65-67. DOI: 10.1111/dth.12197

25. Kim KR, Lee JY, Kim MK, Yoon TY. Erosive pustular dermatosis of the scalp following herpes zoster: successful treatment with topical tacrolimus. Ann Dermatol. 2010;22(2):232-234. doi: 10.5021/ ad.2010.22.2.232

26. Wollenberg A, Heckmann $M$ and Braun-Falco O. Erosive pustular dermatosis of the scalp after zoster ophthalmicus and trauma. Hautarzt. 1992;43(9):576-579.

27. Shall L and Shuttleworth D. Erosive pustular dermatosis of the scalp presenting as herpes zoster. BMJ. 1988;297(6664):1636.

28. Grattan CE. Erosive pustular dermatosis of the scalp following zoster ophthalmicus. J R Coll Gen Pract. 1988;38(315):470-471.

29. Siegel DH, Holland K, Phillips RJ, Drolet BA, Esterly NB and Frieden IJ. Erosive pustular dermatosis of the scalp after perinatal scalp injury. Pediatr Dermatol. 2006;23(6):533-536.

30. Boudaya S, Turki H, Bouassida S, Khemakhem M, Marrakchi S and Zahaf A. Eosinophilic pustular folliculitis in infancy: an unusual case Ann Dermatol Venereol. 2003;130(4):451-454.

31. Caputo R and Veraldi S. Erosive pustular dermatosis of the scalp. J Am Acad Dermatol. 1993;28(1):96-98.

32. Aoshima M, Ito $\mathrm{T}$ and Tokura Y. Erosive pustular dermatosis of the scalp arising concomitantly with elevation of serum matrix metalloproteinase-3 in a patient with rheumatoid arthritis. J Dermatol. 1015;42(5):540-541. DOI:10.1111/1346-8138.12815

33. Yamamoto $T$ and Furuse Y. Erosive pustular dermatosis of the scalp in association with rheumatoid arthritis. Int J Dermatol.1995; 34(2):148.

34.Vaccaro M, Guarneri C, Barbuzza O and Guarneri B. Erosive pustular dermatosis of the scalp: an uncommon condition typical of elderly patients. J Am Geriatr Soc. 2008;56(4):761-762. doi: 10.1111/j.15325415.2008.01615.x.

35. Sawada Y, Bito T, Kawakami C, Shimauchi T, Nakamura M and Tokura
Y. Erosive pustular dermatosis of the scalp and leg associated with myasthenia gravis: A possible pathogenetic role for neutrophilstimulating cytokines and chemokines. Acta Derm Venereol. 2010;90(6):652-653.

36. Mastroianna A, Cota C, Ardigo M, Minutilli E and Berardesca E.Erosive pustular dermatosis of the scalp: a case report and review of the literature. Dermatology. 2005;211(3):273-276.

37. Watanabe S, Takizawa K, Hashimoto N and Ishibashi Y. Pustular dermatosis of the scalp associated with autoimmune diseases. J Dermatol. 1989;16(5):383-387.

38. Watanabne S, Takizawa $\mathrm{K}$, Hashimoto $\mathrm{N}$ and Ishibashi Y. Pustular dermatitis of the scalp associated with autoimmune diseases. J Dermatol 1989;16(5):383-387.

39. Yu X, Liu Y, Ozukum M and Song Z. Erosive pustular dermatosis of the scalp associated with myelodysplastic syndrome. J Eur Acad Dermatol Venereol. 2016;30(2):380-381. doi:10.1111/jdv.12812.

40. Allevato M, Clerc C, Del Sel JM, Donatti L, Cabrera H and Juarez M. Erosive pustular dermatosis of the scalp. Int J Dermatol. 2009;48(11):1213-1216. DOI:10.1111/j.1365-4632.2009.04124.x

41. Yang CS, Juhn H, Cohen LM and Kroumpouzos G. Amino levulinic Acid Photodynamic Therapy in the Treatment of Erosive Pustular Dermatosis of the Scalp: A Case Series. JAMA Dermatol. 2016. doi:10.1001/jamadermatol.2015.6300

42. Eleftheriou LI, McIntee TJ and Stratman EJ. Aminolevulinic acid photodynamic therapy in the treatment of erosive pustular dermatosis of the scalp. Arch Dermatol. 2011;147(12):1368-1370. doi:10.1001/ archdermatol.2011.299.

43. Meyer T, Lopez-Navarro N, Herrera-Acosta E, Jose A and Herrera E. Erosive pustular dermatosis of the scalp: a successful treatment with photodynamic therapy. Photodermatol Photoimmunol Photomed. 2010;26(1):44-45.

44. Jankowski M, Skrzeczko-Kwela E and Czajkowski R. Erosive pustular dermatosis of the scalp treated with $0.1 \%$ mometasone furoate cream. Acta Dermatovenerol Croat. 2014;22(1):67-69.

45.Zahdi MR, Seidel GB, Soares VC, Freitas CF, Mulinari-Brenner FA. Erosive pustular dermatosis of the scalp successfully treated with oral prednisone and topical tacrolimus. An Bras Dermatol. 2013;88(5):796798 doi:10.1590/abd1806-4841.20132109.

46. Cenkowski MJ and Silver S. Topical tacrolimus in the treatment of erosive pustular dermatosis of the scalp. J Cutan Med Surg. 2007;11(6):222-225.

47. Petersen BO and Bygum A. Erosive pustular dermatosis of the scalp: a case treated successfully with isotretinoin. Acta Derm Venereol. 2008;88(3):300-301. doi:10.2340/00015555-0416.

48. Ikeda M, Arata J and Isaka H. Erosive pustular dermatosis of the scalp successfully treated with oral zinc sulphate. $\mathrm{Br}$ J Dermatol. 1982;106(6):742-743.

49. Boffa MJ. Erosive pustular dermatosis of the scalp successfully treated with calcipotriol cream. Br J Dermatol. 2003;148(3):593-595.

50. Tardio NB and Daly TJ. Erosive pustular dermatosis and associated alopecia successfully treated with topical tacrolimus. J Am AcadDermatol. 2011;65(3):e93-94. doi:10.1016/j.jaad.2011.05.008.

51. Dall'Olio E, Rosina P and Girolomoni G. Erosive pustular dermatosis of the leg: long-term control with topical tacrolimus. Australas J Dermatol. 2011;52(1):e15-17. Doi:10.1111/j.1440-0960.2009.00584.x. 
52. Seez M, Rodriguez-Martin M, Sidro M, Carnerero A, Garcia-Bustinduy $M$ and Noda A. Successful Treatment of erosive pustular dermatosis of the scalp with topical tacrolimus. Clin Exp Dermatol. 2005;30(5):599600.

53. Laffitte E, Kaya G, Piguet V and Saurat JH. Erosive pustular dermatosis of the scalp: treatment with topical tacrolimus. Arch Dermatol. 2003;139(6):712-714. doi:10.1001/archderm.139.6.712.

54. Broussard KC, Berger TG, Rosenblum M and Murase JE. Erosive pustular dermatosis of the scalp: a review with a focus on dapsone therapy. J Am Acad Dermatol. 2012;66(4):680-686. doi:10.1016/j. jaad.2011.10.011
55. Darwich E, Munoz-Santos C and Mascaro JM Jr. Erosive pustular dermatosis of the scalp responding to acitretin. Arch Dermatol. 2011;147(2):252-253. doi: 10.1001/archdermatol.2010.442.

56. Di Lernia V and Ricci C. Familial erosive pustular dermatosis of the scalp and legs successfully treated with ciclosporin. Clin Exp Dermatol. 2016;41(3):334-335. Doi:10.1111/ced.12744.

57. Semkova K, Georgi Tchernev, and Uwe Wollina. Erosive pustular dermatosis (chronic atrophic dermatosis of the scalp and extremities). Clin Cosmet ilnvestig Dermatol. 2013;6:177-82. doi: 10.2147/CCID. S47019. 